
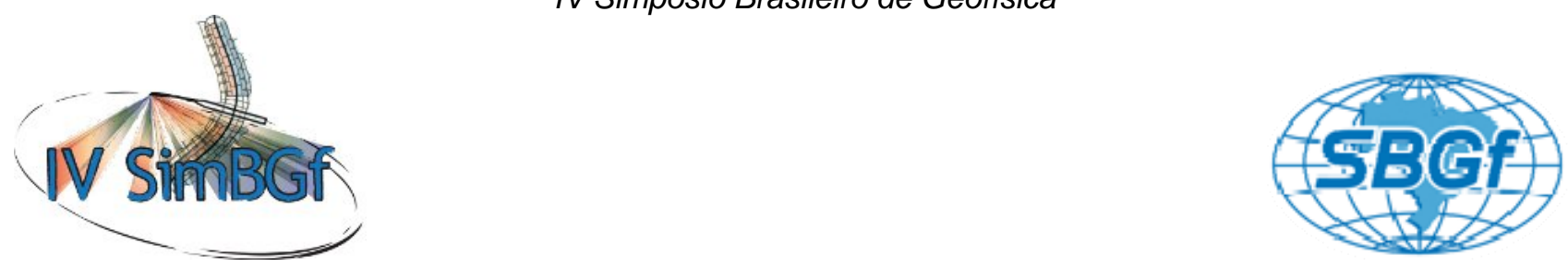

\title{
Estudo de Sítio Arqueológico pelos métodos Magnéticos e Radiométricos: São Miguel das Missões -RS
}

*Mateus Perin Padilha, Universidade Federal do Pampa Manuel Iván Zevallos Abarca, Universidade Federal do Pampa

Copyright 2010, SBGf - Sociedade Brasileira de Geofísica

Este texto foi preparado para a apresentação no IV Simpósio Brasileiro de Geofísica, Brasília, 14 a 17 de novembro de 2010. Seu conteúdo foi revisado pelo Comitê Técnico do IV SimBGf, mas não necessariamente representa a opinião da SBGf ou de seus associados. É proibida a reprodução total ou parcial deste material para propósitos comerciais sem prévia autorização da SBGf.

\section{Abstract}

The studied region was heavily marked by human activities in past ages, enabling the assessment of an extraordinary amount of data and traces of the region.

The expeditions made at archaeological sites counted with data aquisition both the method radiometric as magnetic. These methods investigate the possibility of artifacts buried in the Archaeological Site of São Miguel das Missões (RS) and thus contribute to the region historically.

\section{Introdução}

A busca para ampliar o desenvolvimento da aplicação de métodos a pesquisas nessa área foram realizadas no Museu a Céu Aberto (MCA) que corresponde ao Sítio Arqueológico de São Miguel das Missões (RS) e seu entorno Figura 1.

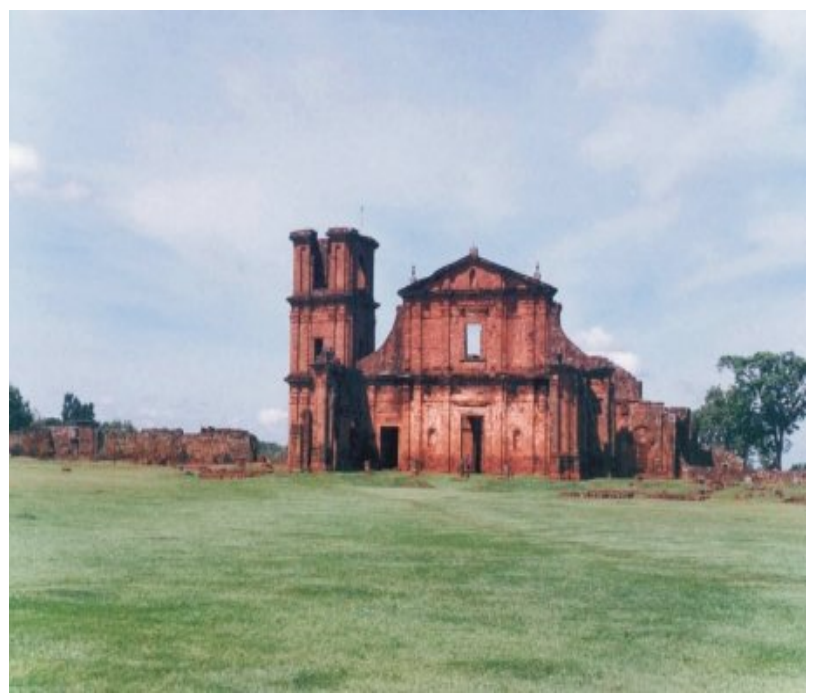

Figura 1: MCA (Museu a Céu Aberto do sítio arqueológico de São Miguel das Missões).
A medida que o estudo avançava o foco foi direcionado ao método Radiométrico e Magnético, estes investigaram a partir das aquisições, possíveis formas de sobrevivência dos povos que habitavam aquela região, como o fogo de chão usado para cozinhar seus alimentos e as plantações antigas que necessitavam de revolver a terra. Assim as anomalias geradas podem ser interpretadas em base nos fatos históricos já desenvolvidos.

\section{Metodologia}

Esta pesquisa pretende aplicar os métodos Magnéticos e Radiométricos para a busca de sítios arqueológicos na região de São Miguel das Missões- Rs, Figura 2.

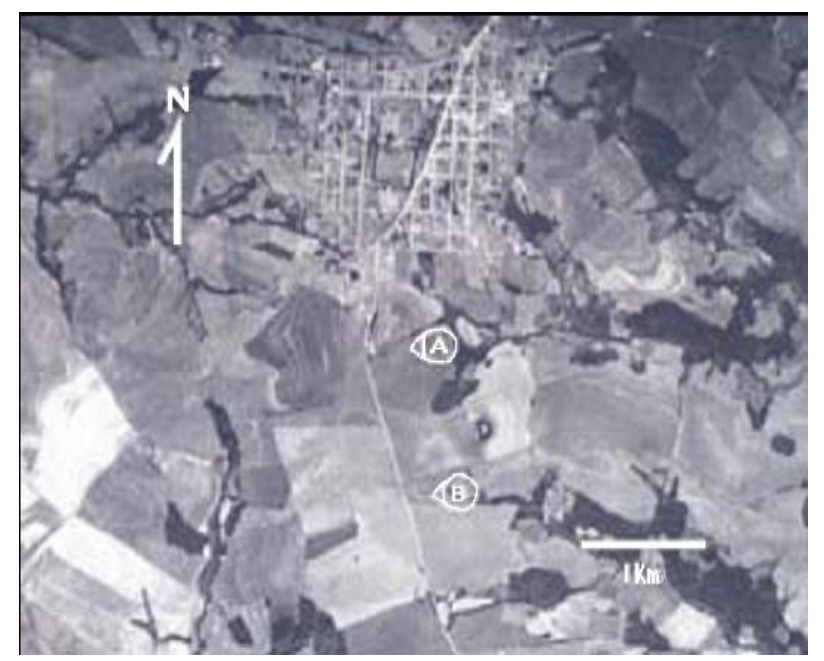

Figura 2: Possíveis indícios arqueológicos, na cidade de São M. das Missões e entorno datado em 1985.

Segundo Nowatzki (2006) as setas A e B indicam possíveis segmentos de antigas estradas missionárias.

Os perfis que serão realizados, pelo método magnético, sobre a zona de interesse arqueológico terão orientação Norte-Sul. Estima-se que serão feitos perfis em uma área de 50X100 m; sendo 5000 metros de área desta forma totalizando 5100 metros lineares de medidas magnéticas. 
O levantamento Radiométrico será efetuado a partir da Espectrometria de Radiação Gama com medições sobre os mesmos perfis de Magnetometria, desta forma podendo ter uma boa qualificação sobre a interpretação da anomalia..

O método será elaborado em tomadas de contagem por minuto, e assim assimilada com a contagem da porcentagem gradual de K, Th e U.

\section{Resultados}

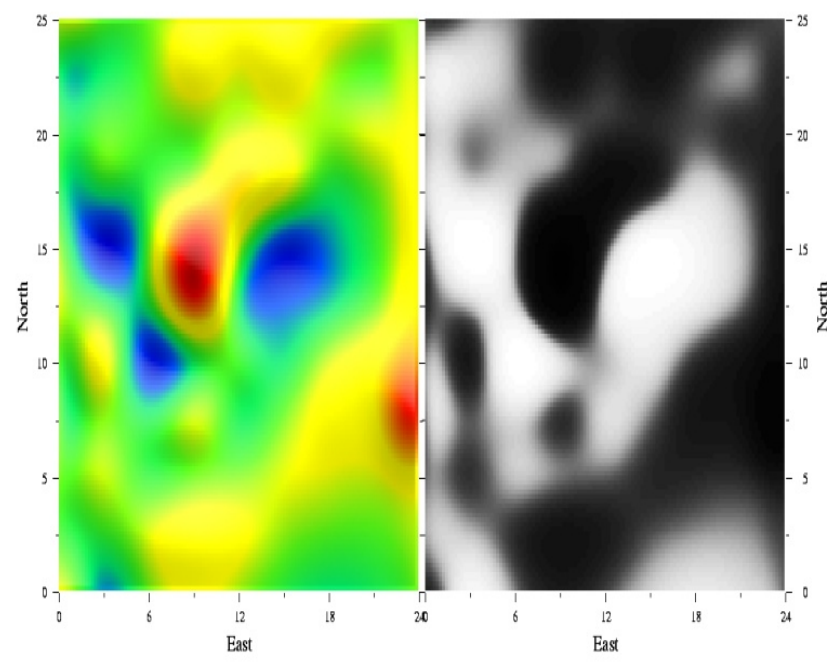

Figura 3: Anomalia magnética bipolar do campo total, interpretado como artefatos soterrados.

O mapa magnético da figura 3 mostra uma anomalia magnética dipolar do campo total. A forma da anomalia é típica para o hemisfério Sul magnético e indica um forte contraste na propriedade de susceptibilidade magnética dos materiais em subsuperficie.

Possivelmente os dados esperados de susceptibilidade magnética poderão sugerir feições delimitadoras de materiais magnetizáveis, com estratos compostos por áreas de terra revolvida, possivelmente rica em matéria orgânica e materiais queimados misturados, essa interpretação é válida para as plantações e os métodos de sobrevivência dos povos.

Em contrapartida possíveis interpretações sobre a natureza dos corpos que estão gerando esta anomalia vão de fogos de chão (lenha) até artefatos soterrados. Desta forma a escavação serve para comprovar a anomalia representada na Figura 3. Esta etapa não foi possível realizar, pois precisa de autorização especial para tal ato, sabe-se que o sítio arqueológico de São Miguel das Missões tem grande contexto histórico.

O levantamento Radiométrico, neste caso foi determinado para ampliar as informações sobre as pressupostas anomalias magnéticas, desta forma determina as feições que delimitam os corpos.
A interpretação qualitativa torna-se um pouco difícil, pois com os dois métodos disponíveis ainda ficou complexo relacionar a quantidade e tamanho dos materiais envolvidos, essa relação define os campos gerados pelos mesmos.

\section{Discussão e Conclusões}

A Geofísica é uma ferramenta auxiliar na delimitação e posicionamento das anomalias, com evidencias de áreas arqueológicas. Tendo em vista que esta área é tombada como patrimônio Nacional e se tem o conhecimento do grande material arqueológico existente em subsuperficie. Espera-se com os métodos geofísicos aplicados, delimitar as áreas com maior concentração destes materiais. Cabe ressaltar que a comprovação destas áreas limitadas em geral não podem ser verificadas (sem fazer escavações).

Levando em consideração que este método aplicado não tem como finalidade a substituição da importância do arqueólogo, mas sim uma ferramenta auxiliar para a prospecção arqueológica.

Os métodos geofísicos não substituem a etapa de escavação que se faz indispensável à investigação dos pontos anômalos e também na interpretação do significado de cada feição ou estrutura arqueológica.

Desta forma temos a evidência de utilidade dos métodos Magnéticos e Radiométricos para prospectar restos arqueológicos.

As anomalias magnéticas encontradas podem ser atribuídas a elementos de origem cultural e histórico que indicam a atividade da população que habitavam estas zonas.

Também foi muito importante conhecer as características do sítio antes de se iniciar um levantamento, pois nem sempre a aplicação de um determinado método é suficiente para o entendimento total do seu meio, fazendo-se necessária a integração de outros métodos geofísicos sobre o campo de aquisição de dados, que neste caso foi o método Radiométrico e o método Magnético.

\section{Referências}

Alberto, J. J. A., Rocha, E. B., Mendonça, C. A., Porsani, J. L., Brito, P. M. A., Hiodo, F. Y., 2000. Geophysical Prospecting Techniques to Delineate Fluvial Prehistoric Shell Deposits (Sambaqui). In: Archaeological Site of Miracatú-Sp. $31^{\text {st }}$ International Geological Congress, Rio de Janeiro, Brazil.

Barba, L., Manzanilla, L., 1988. Superficie / Escavación. Un ensayo de predicción de rasgos arqueológicos en Oztoya-hualco, Valle de Teotihuacan, Antropologicas $\mathrm{n}^{\circ} 1$, México,19-46.

Nowatzki, C., H,. 2006. Geologia arqueológica: Uma ferramenta no aprendizado de futuros museólogos. 
Encontro Nacional de Museus-ICOM, São Miguel das Missões, Brasil. 
